François Charron est né à Longueuil en 1952. Après des études universitaires et quatre années passées dans l'enseignement, il se consacre entièrement à son travail de création. Il a fait paraître près d'une trentaine d'ouvrages, principalement aux Herbes Rouges, depuis 1972. Considéré comme le poète le plus controversé de sa génération, sa production récente vise à un dépouillement de plus en plus radical de l'écriture. Il a mérité le prix Emile-Nelligan pour son recueil Blessures, ainsi que le prix Canada-Belgique pour l'ensemble de son oeuvre. Son dernier livre a pour titre La Beauté pourrit sans douleur.

\title{
Là où nous sommes
}

je touche à ces feuilles

la lumière s'infiltre

cette terre, lentement, qui nous parle ce regard tout comme la terre entre nous

le blanc s'ouvre
je me sens être

tu me montres une flamme au fond de toi il y a notre enfance encore fragile entre nos mains je reconnais l'abîme d'une rose

les couleurs des feuilles qui changent autour de la maison, un certain froid 
bientôt la pluie, l'orage

je suis solitaire

hors de moi la pensée, le souffle brûlant

ici même, le soir pur dans mon dos

les reflets sur l'étang se défont

je ne crains plus le silence de ma voix

la montagne m'a tiré vers elle une porte a disparu

j'écris que le poème est le lieu vrai du monde

ton corps nu nomme Dieu

ta figure s'éveille pour entrer je ne sais où

on peut avoir le goût de rester là

sans but, sans raison, sans profondeur

comme une chose réelle qui échappe au présent parce qu'elle existe

la lune pour endormir la terre

le mur droit au bord de l'océan

ce feu très lent sur le rectangle de la table 
devant la nuit qui est vide, de la paille m'a enseigné

tu tiens un morceau de bois desséché

le village se recueille

on imagine des gens qui dorment encore

la vie dure un instant

je cours vers toi

les pierres font de l'ombre à nos côtés

quelqu'un nous arrête

nous sommes le hasard, le regard du ciel

notre chaleur au-dessus du sol existe

un cahier demeure ouvert sur ma table de travail

l'espace abandonne ce que je dis

tu m'embrasses avec des fleurs

il y a cette chambre immobile qui nous devance

la distance est un souvenir important

où irons-nous? que ferons-nous?

un poème se défait dans l'air sec. 